3. To make every examination as short as is possible, thereby lessening the total amount of rays to be absorbed.

4. To use intensifying screens when practicable.

5. To use filters for the elimination of the softer rays.

6. To confine the rays to the part actually under examination.

Burns of the operator may be avoided: (1) by keeping entirelv out of the field of rays, by working from an adjoining room, with lead-lined walls between, or by the use of lead-lined cabinets; (2) by confining the rays about the tube so that the only way of exit is through the aperture made for the examination of the patient; (3) by means of protecting shields, aprons, gloves, masks, etc. In fact, all these should be combined.

Burns during Roentgen therapy may be aroided, (1) by following the same general principles referred to in diagnosis; (2) by measuring each dose given and never exceeding the limit of skin toleration as indicated by the dose meter; (3) by allowing an interval of three weeks between the repetitions of the dose on any particular area of skin; (4) by the use of more filtration than would be used in diagnostic work; (5) by keeping in mind the fact that epithelium and glandular tissue are more sensitive than other tissue to the rays; $(6)$ bv avoiding any other form of irritation on the skin treated, such as counterirritation, high-frequency currents, liniments, stimulating ointments, antiseptics, etc.

The details necessary in carrying out the foregoing principles will vary with the individual operator and his circumstances, but they should receive the most careful attention. I believe that roentgenology is more distinctly a specialty than any other, because to master it one must be a good physician, must have a good general knowledge of pathology both in general medicine and the specialties, must have a large equipment, must give much time to the mastery of details, and must always be cautious.

1321 Spruce Street.

\section{TREATMENT OF TETANUS BY THE "RATIONAL" METHOD OF ASHHURS'T AND JOHN}

THE DFVELOPMENT OF SUPPURATIVE SERUM (ASEPTIC) MENINGITIS FOLLOWING THE INTRASPINAL INJECTION OF TETANUS ANTITOXIN; WITH REPORT OF A CASE *

WALTER V. BREM, M.D. LOS ANGELES

In a recent article on the treatment of tetanus, Ashhurst and John ${ }^{1}$ conclude that the rational use of tetanus antitoxin consists in (1) the intraneural injection of antitoxin; (2) the intraspinal injection; (3) the intravenous injection, and (4) the infiltration of the tissues about the site of the injury.

The quantity used.should be very much greater than the quantity that has usually been given heretofore by the subcutaneous route. In one of their cases in which the subcutaneous route was used, 224,000 units were

* Read at the menting of the Los Angeles County Medical Assoclation, Oct. 16,1913 .

1. Ashhurst. A. P. C., and John, R. L. : The Rational Treatment if. administered in three days. But such an enormous quantity is not demanded when the intraneural and intraspinal routes are chosen. These authors feel that the outlook for patients with tetanus is much brighter now since the development of this method of administering antitoxin, and that the old view, that antitoxin is of no avail after the symptoms of tetanus have developed, must be abandoned.

In 1910, at Colon Hospital, Canal Zone, I treated four cases of tetanus by intraneural, intravenous and subcutaneous injections of antitoxin, and used chlorbutanol (chloretone) and morphin as sedatives. These cases are reported in detail by Hill. ${ }^{2}$

One of these patients, whose case was a severe one with a ten-day incubation period, recovered. From this patient the infecting tetanus bacillus was passed through a series of guinea-pigs. 'The last two of these pigs, after local tetanus was well developed, were treated by postorbital injection of 1 c.c. of tetanus antitoxin. One pig recovered, and the other seemed to be recovering when it was accidentally killed by a subcutaneous injection of chlorbutanol in alcohol. Smears made from the wounds showed Gram-positive bacilli that appeared to be in all stages of degeneration. This was shown by great swelling and granulation of the bacilli, atvoical shapes, and the absence of spore formation. Furthermore, the splinter which had been removed from the patient's wound and had been used in successive inoculations, failed to infect another pig when removed from the last-treated animal. The dosage used in treating these animals postorbitally was equivalent to about 30,000 units in an adult man.

I. have not had an opportunity since then to examine the results that I obtained in the treatment of these guinea-pigs, but I felt the results suggestive enough to warrant the use of intraspinal injections in future cases of tetanus. I was ready, therefore, to accept the views of Ashhurst and John when their article appeared, and shortly afterward I had an opportunity to apply, successfully, their methods to the treatment of a patient with cephalic tetanus, which developed after a six-day incubation period.

\section{REPORT OF CASE}

Injury by baseball on upper lip; six-day incubation period; gradual onset; intraneural, intraspinal and intravenous injection of 98,000 units of tetanus antitoxin and infiltration of lip about the injury; suppurative serum (aseptic) meningitis follouing intraspinal injection of antitoxin; rapid rocovery.

The case occurred in the private practice of Dr. P. Newmark of Los Angeles, who called me in consultation and requested me to treat the patient. I wish to thank Dr. Newmark here for permitting me to publish the case-report, and for his courtesy and encouragement during the trying days of the treatment.

History.-The patient was a robust man aged 2l. He had been struck on the left side of the upper lip by a baseball on Saturday, July 12, 1913. The blow caused an abrasion of the skin, and the mucous surface of the lip was cut by the impact against a tooth. The skin abrasion was treated with hydrogen peroxid by the patient's mother several hours after the injury occurred. Healing of the wounds, both inside and outside, was rapid. On Friday evening, July 18, the patient's teeth clamped down tightly on a cigar that he had begun to smoke, and he noticed that his jaws were stiff. His jaws were stiffer on Saturday, the 19th, and he began to feel pain in his back. He called on Dr. Newmark on this date, but not finding him he did not see him until Sunday afternoon, July 20 , when the back was more painful and was stiff and the jaws were about as stiff as on the day before. The patient

2. Hill, E. W. : Tetanus, Arch. Int. Med., Dec., 1911, p. 747. 
was taking only liquid nourishment. On Sunday evening I saw the patient with Dr. Newmark, who suspected tetanus.

Physical Examination.-July 20,8 p. m.: The patient was sitting up in bed, smiling and talking. His speech was somewhat thick and his jaws seemed stiff. He was a well-nourished, robust young man. The teeth could be separated only $1 \mathrm{~cm}$. There was a slightly indurated area on the left side of the upper lip, and a scar on the corresponding mucous surface. The throat was not sore, and there were no tender teeth or swollen gums, and no enlargement of the cervical lymph-nodes. Examination of the heart, lungs and abdominal viscera revealed nothing abnormal. The back was stiff, and flexion of the body caused pain. The neck was not stiff, and the chin could be lowered almost to the sternum.

Reflexes: The patellar reflexes were much exaggerated; there was no ankle-clonus; Kernig's sign was not present though the hamstring tendons were quite tense when the leg was extended; the superficial and deep abdominal reflexes were exaggerated, and also the cremasteric reflex. Reflexes of the upper extremities were about normal.

At this time 8,000 units of tetanus antitoxin were given subcutaneously.

July 21, 8 p. m.: Dr. H. G. Brainerd was called in consultation and he confirmed the diagnosis of tetanus. The patient's jaws were perhaps slightly stiffer, his neck muscles were growing stiff, his back was slightly bent backward and his chest thrown out, giving a pouter-pigeon effect. The reflexes were increased more than on the $20 \mathrm{th}$, and the biceps reflex was exaggerated. There had been no convulsions. The patient was removed to the hospital and prepared for operation for the intraneural injection of the left facial nerve. Before the operation he complained of great pain in his back and he showed definite opisthotonic spasms.

The left facial nerve was exposed by Dr. F. S. Ray, who cut down through the left parotid gland. An unknown, but small, quantity of tetanus antitoxin was injected into the sheath of the nerve, and the surrounding tissues were infiltrated. A small drain was left in the wound. A lumbar puneture was then made and about 20 c.c. of cerebrospinal fluid were removed and 13,000 units of antitoxin injected; 10,000 units were then given intravenously, and the site of the injury on the lip was infiltrated with 2,000 units.

The cerebrospinal fluid was clear, pressure $170 \mathrm{~mm}$. in a capillary tube, no cells were seen in 1 c.mm., the butyric acid test was doubtful (reaction \pm ), with 0.2 c.c. Wassermann test negative. Five c.e. of the fluid were injected subcutaneously into a guinea-pig, which remained well.

July 22,9 a. m.: The patient romited twice after the operation. The temperature was 101.4, the pulse 84. There was severe headache and backache. The jaws were opened less widely, the back was stiff and there was a tendency to opisthotonos. Sixty grains of chlorbutanol in olive-oil by rectum, and $1 / 4$ grain morphin hypodermically were ordered according as circumstances might require.

3 p. m.: Condition was the same. Kernig's sign was marked. Tetanus antitoxin, 20,000 units intravenously and 10,000 units intraspinally, was injected.

Cerebrospinal Fluid: Fifteen c.c. of turbid, whitish fluid were obtained. Pressure was $210 \mathrm{~mm}$. The cells numbered 3,940 per cubic millimeter; polymorphonuclear neutrophils predominated, but there were many lymphocytes and endothelial cells. Stained smears from the centrifugalized sediment showed no bacteria. Aerobic and anaerobic cultures on blood-agar and hydrocele-agar remained sterile. Aerobic and anaerobic cultures from Cutter's and Parke, Davis \& Co.'s antitetanus serums remained sterile.

July 23, 9 a. m.: Patient's condition was about the same as yesterday. The signs of meningitis were well marked, and almost obscured the signs of tetanus. Temperature was 101.8, pulse from 40 to 60 ; there was severe headache and backache, the neck was stiff, Kernig's sign was marked; chest protruded, abdominal and spinal muscles were hard, spine curved backward. There was facial paralysis on left. The operative wound was clean.
3 p. m.: Tetanus antitoxin, 10,000 units, was given intravenously. By lumbar puncture about $2 \tilde{5}$ c.e. of turbid, whitish fluid were obtained. It was more cloudy than on yesterday. Pressure was $340+\mathrm{mm}$. The cells showed great predominance of polymorphonuclears and fewer lymphocytes and endothelial cells than on yesterday. Smears and cultures (aerobic and anaerobic on hydrocele-agar) were negative for organisms.

July 24, 9 a. m.: Patient's condition was improved, headache was not so severe, jaws opened more widely, neck and back were not so stiff, patellar reflexes were still exaggerated, Kernig's sign was marked, and there was no ankle-clonus.

3 p. m.: Tetanus antitoxin, 10,000 units, was given intravenously. By lumbar puncture about 20 c.c. of fluid were obtained. It was less turbid than on yesterday; pressure 300 $\mathrm{mm}$. Cell-count showed 1,020 per cubic millimeter, poly. morphonuclears predominating; there were only a few lymplocytes and endothelial cells. Smears were negative for organ isms. Cultures (aerobic and anaerobic on hydrocele-agar) remained sterile.

July 25, 9 a. m.: Patient's condition was much improved, temperature was normal, there was no headache, neck and back were much less stiff, jaws opened widely, left facial paralysis was gradually clearing up, and Kernig's sign was present but less marked.

5 p. m.: Tetanus antitoxin, 10,000 units, was given intravenously. No lumbar puncture was made.

July 26, 9 a. m.: Condition was greatly improved. Temperature was normal, pulse 72 . There was no headache; jaws were widely opened; Kernig's sign was present but less pronounced, and patellar reflexes were slightly exaggerated. The patient was bright and felt well and hungry. His bowels had moved well, but he had not been able to void urine voluntarily since the operation and had had to be catheterized. No antitoxin was given to-day and no lumbar puncture made.

July 28, 9 a. m.: Condition was excellent, temperature and pulse normal, no headache, appetite good, bowels normal, urination spontaneous, mouth opened widely, facial paralysis was improving, patellar reflexes were slightly exaggerated, Kernig's sign was present when thigh was flexed on abdomen, but negative when flexed to a right angle. Patient was discharged from the hospital.

Subsequent History. - The patient convalesced rapidly, though his reflexes remained slightly exaggerated for about two weeks. The facial paralysis had almost disappeared three weeks after the operation. During convalescence the skin over the left parotid gland puffed up with parotid secretion, which formed a fluctuating mass without redness, pain or local heat. Dr. Ray aspirated the fluid with a hypodermic syringe several times and put on a dressing with slight pressure. This quickly checked the secretion and healing was complete.

Summary.-Young man of 21 years, cephalic tetanus, six days' incubation period, gradual onset, treatment begun eight days after injury and two days after onset of symptoms; intraneural injection of unknown but small quantity of tetanus antitoxin into left facial nerve; intraspinal injections of 23,000 units; intravenous injections of 60,000 units; subcutaneous injection of 8,000 units; infiltration of tissues about site of injury with 2,000 units, total quantity of antitoxin 98,000 units; development of meningitis within six hours after first intraspinal injection, purulent fluid sterile by microscopic and cultural aerobic and anaerobic examination; rapid recov. ery from tetanus and meningitis.

\section{DISCUSSION}

Cephalic tetanus is a very fatal type of the disease, and the outlook is extremely grave in any type with an incubation period of only six days, the mortality being from 60 to 80 per cent. In the case here reported the type of the disease and the incubation period would indicate a grave prognosis, and one is tempted to grow enthusiastic over the method of treatment that was asso. ciated with such a prompt recovery. But it must ba reniembered that the onset of symptoms in the case was 
very gradual, which is a favorable prognostic sign, and that there was some chance of the patient's recovery without the antitoxin. Nevertheless, the recovery of the patient, and especially the very rapid recovery, gives great encouragement for the future treatment of tetanus along the lines suggested by Ashhurst and John.

A phenomenon of almost as great interest as the recovery under the treatment given was the development of a true suppurative meningitis, with all the clinical signs of meningitis, following the intraspinal injection of tetanus antitoxin. This was proved to be, without doubt, of non-bacterial origin bv the microscopic examination of the cerebrospinal fluid, by aerobic and anaerobic cultures, and by the recovery of the patient. The reaction did not appear to be due to hypersensitiveness to the horse-serum, for the patient had never before this illness been given antitoxin of any kind, he was not an asthmatic, nor did he have any reaction when given 8,000 units subcutaneonsly of tetanus antitoxin the night before the intraspinal injection.

In the literature that I have been able to examine, the only references to aseptic meningitis following the intraspinal injection of serum are made by Sophian ${ }^{3}$ and by Sladen. ${ }^{4}$ Sophian says:

In this group (aseptic meningitis) may be mentioned cases showing clear fluid on lumbar puncture lut with clinical symptoms of meningitis sufficiently suspicious to warrant the intraspinal administration of serum. Such cases will frequently give a turbid, purulent, sterile fluid at a later puncture also as a result of the reaction set up by the serum. No damage, however, results in such cases, as the fluid clears up in a few days with no after-effects.

The proof is not absolute in this group of cases that the purulent meningitis was a reaction to the serum, for before the serum was given the patients had "clinical symptoms of meningitis sufficiently suspicious to warrant the intraspinal administration of serum."

When the cerebrospinal fluid is examined very early in meningococcus meningitis it may not be purulent and may show no meningococci. If serum is injected at this time, the fluid may still become purulent and ret the scrum may prevent the appearance of meningococci. The cases spoken of by Sophian do not present. therefore, conclusive evidence of a serum meningitis, but they are very suggestive.

Slaclen, in discussing the effect of the injection of antimeningitis serum on the spinal fluid, says:

In every case there is a very constant, positive chemotaxis for polymorphonuclear leukocytes in the spinal fluid. This has been observed in one case of influenzal meningitis. In six cases of tuberculous meningitis the clear spinal fluid with predominating small mononuclear cells has become clonded with polymorphonuclears after serum, and the small mononuclear cells have totally disappeared.

These observations of Sophian and Sladen and my own case seem to demonstrate conclusively that the introduction of a foreign serum into the spinal canal may cause a reaction that presents all the clinical and pathologic evidences of an acute suppurative meningitis, except that no bacteria can be demonstrated in the purulent cerebrospinal fluid. It seems plausible, furthermore, that the exacerbations frequently following the intraspinal injections of serum in meningococcus meningitis are due to the reaction to the horse-serum, and

3. Sophian. A.: Epidemic Cerebrospinal Meningitis, St. Louis, 3. Sophian, A.: Epidemic Cerebros
C. V. Mosby Company, 1913, p. 100.

4. Sladen, F. J.: The Serum Treatment of Meningitis, Tre Jovrial A. M. A., Oct 17, 1908, p. 1318. that it is independent of the condition of hypersensitiveness.

These facts are of the greatest importance to those who are called on to inject substances intraspinally. This route for therapeutic measures is being used more and more frequently, and it is probable that many instances of serum meningitis will be seen. It will be interesting to know whether or not the intraspinal injection of salvarsanized human serum by the method of Swift and Ellis ${ }^{5}$ may sometimes stimulate the reaction. These authors ${ }^{6}$ report a great increase of cells in the cerebrospinal fluid of normal monkeys after the intraspinal injection of salvarsanized monkey-serum, and that the cells causing the increase were chiefly polvmorphonuclears. In one instance the number reached over 4,000 . I have seen an increase of cells in two patients two weeks after an intraspinal injection of salvarsanized serum, and in one case there were 22 per cent. of polymorphonuclears. It is probable that the number of cells and the percentage of polymorphonuclears would have been much greater if the fluid had been examined shortly after treatment.

When a meningitis reaction does occur it may be very alarming, especially if one is not cognizant of the fact that such a purulent meningitis may be sterile and caused entirely by the serum. I myself was not aware of it at the time my case occurred, and I felt that I had infected the patient during the intraspinal injection. Happily, this was not true, and I trust that the publication of the case-report may save some one else the stress of feeling that he has superimposed a bacterial meningitis on a case of tetanus.

NoTE.-Since submitting this report for publication I have found a report by J. A. Sicard, "Serous Meningitis and Anaphylaxis after Spinal Serotherapy," Presse Méd., xviii, No. 92: abstr. The Journal A. M. A., Jan. 7,1911, p. 78) in which he states that he encountered the reaction from the intraspinal injection of antimeningitis serum in nervous and mental cases. After the injection these patients developed fever, headache, nausea a suggestion of Kernig's sign, and pains in the legs. The cerebrospinal fluid became turbid and showed a polynucleosis gradually yielding to lymphocytosis. Sicard suggests that in acute meningitis the symptoms have masked those due to the serum reaction, which explains why the latter have not been recognized before. He states that the reaction has nothing to do with anaphylaxis as it occurs with the first injection.

423 Security Building.

\section{A NEW AND LOGICAL TREATMENT FOR ALCOHOLISM}

A PRELIMINARY REPORT

B. L. SPITZIG, M.D. CLEVELAND

Personal observation of the effects of the treatment proposed in this communication extends over a period of two rears. Although this study is too incomplete to determine the permanency of the therapy advocated, yet the progress of the limited subjects treated is so unassailable that I consider this field for investigation worthy of proposal to others for more extended research.

The type of patient governs largely the success or failure of this treatment. The derelict who has no ambition

5. Swift, H. F., and Ellis, A. W. M. : The Treatment of Syph ilitic Affections of the Central Nervous system, with Especial Ref erence to the Use of Intraspinous Injections, Arch. Int. Med., Sep temlyer. 1913 , p. 331 .

6. Ellis, A. W. M., and Swift, H. F.: The Effect of Intraspinous Injections of Salvarsan and Neosalvarsan in Monkeys, Jour. Exper. Med.. 1913, xviii, 428. 